\title{
Vibration-based Condition Monitoring of Industrial Drivetrains Operating under Non-stationary Conditions
}

\author{
Madhurjya Dev Choudhury \\ University of Auckland, New Zealand \\ mcho491@aucklanduni.ac.nz
}

\begin{abstract}
This research is focused on advancing the state-of-the art in fault diagnostics of industrial drivetrains. It is proposed to develop a fault detection algorithm and fault severity prediction model for critical drivetrain components using measured vibration signals. The fault detection algorithm will be developed to overcome the challenge of extracting reliable fault information for drivetrains operating under speed and load fluctuations, whereas the severity prediction model will aid in predicting the degradation level of a faulty component. The results of this research can, therefore, help in improving the availability of industrial drivetrains, by providing a dependable platform to the maintenance personnel for proper decision-making.
\end{abstract}

\section{Problem Statement}

Drivetrains are at the heart of operation in a wide range of industries like automotive, manufacturing, and energy generation (Lei, Lin, Zuo \& He, 2014). Therefore, its robustness and reliability are of utmost importance. Any fault in them has a potential to cause major economic losses as well as a catastrophic accident (Lei et al., 2014). Condition based health monitoring via processing of system signal measurements plays an important role in improving the robustness and reliability of such drivetrains. It can significantly reduce plant downtime, cost of maintenance and help to avoid accidents caused by machine failure (Sheng, 2012). In order to design a robust condition monitoring system, it is essential to understand the different failure modes of a drivetrain so that the components that require continuous monitoring and are susceptible to failures can be identified. Most of the failure databases indicate that majority of the drivetrain failures can be attributed to defects in bearings and gears (Lei et al., 2014). Therefore, it is important to detect faults in them to avoid drivetrain failures. Traditionally, vibration signal based analysis is employed for

Madhurjya Dev Choudhury. This is an open-access article distributed under the terms of the Creative Commons Attribution 3.0 United States License, which permits unrestricted use, distribution, and reproduction in any medium, provided the original author and source are credited. continuous monitoring of bearings and gears, in which vibration sensors like accelerometer etc., are mounted in and around the monitoring component. A local defect in a bearing or a gear induces a periodic impulse in the vibration signal, each time the defect strikes other contacting or mating parts. These impulse responses present in the measured signal occur at a certain frequency called the fault characteristic frequency (FCF). Therefore, bearing and gear faults can be detected in the frequency domain by identifying these FCFs. However, extracting reliable fault information from measured vibration signals is challenging because the FCFs are related to the shaft rotating frequency, which varies during operation (Rai \& Upadhyay, 2016). This operating speed fluctuation results in a non-stationary nature of the collected vibration signal. Moreover, the measured signal is also often contaminated by interferences and random noise (Rai \& Upadhyay, 2016). These factors smear the FCFs in the frequency spectrum. Hence, there are two issues in bearing and gear fault detection using vibration signals: (1) fault features extraction from the contaminated signal, and (2) fault detection under timevarying speed conditions.

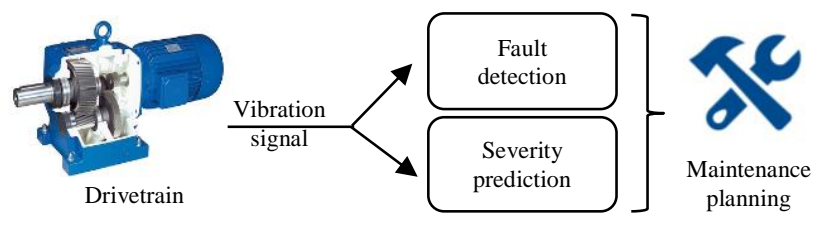

Figure 1. Flow of the project, with the red zone emphaising the area of interest.

Another important issue in condition monitoring, under speed fluctuation, is the effective assessment of a faulty component's degradation level by predicting the type and severity of the fault (Cerrada, Sanchez, Li, Pacheco, Cabrera, Oliveira \& Vasquez, 2018). Fault detection is generally limited by the result of knowing whether a component is in a different condition from the normal healthy state. Therefore, it is essential to devise an indicator to measure the severity of the fault, which can be defined to determine the level of a component's defect at each monitored interval. Such indicators allow an operator to monitor if a considered faulty component's condition gets worse or it remains stable, which 
helps in proper maintenance decision-making (as highlighted in Fig. 1).

\section{EXPECTED CONTRIBUTIONS}

The results of this research will be used for extracting reliable fault information in an industrial drivetrain operating under realistic conditions. Studying the failure mechanism of critical drivetrain components, like bearings and gears, is important to understand their health condition that can help in providing critical inputs for operation and maintenance $(\mathrm{O} \& \mathrm{M})$ optimization. The expected contributions of this research will be,

1. A new self-adaptive fault detection approach for gears and bearings under time-varying operating conditions.

2. A signal processing based fault severity model to monitor the performance degradation in bearings, thereby assisting in the development of a robust condition monitoring system.

\section{Research Plan}

The proposed research is divided into four objectives as discussed below,

Objective 1: Investigate vibration signal characteristics of critical drivetrain components to understand failure mechanisms.

Objective 2: Develop advanced signal processing based fault detection methods for critical drivetrain components operating under realistic conditions like time-varying speed operation.

Objective 3: Develop methods to classify the level of failure. Objective 4: Experimental validation of the proposed diagnostic algorithms on measured signals from industrial drivetrains, like wind turbines and a test-rig, capable of producing faults under realistic conditions typically observed in an industrial-scale drivetrain.

The aforementioned objectives and other activities of this research will be pursued according to the proposed schedule highlighted in Table 1.

\subsection{Work Performed}

This PhD started with a survey of literature in the area of fault diagnostics in industrial drivetrains, which revealed that bearings and gears are the most critical components that affect the health of a drivetrain. Work has already been performed for developing a fault detection algorithm for gears operating under time-varying conditions (Choudhury, Hong \& Dhupia, 2018). Analytical gear fault models were studied to understand the vibration signal characteristics of both fixed-axis and planetary gears operating under different speed and load conditions. This understanding was utilized to develop a novel frequency domain self-adaptive fault detection algorithm for gears, combining variational mode decomposition (VMD) with dynamic time warping (DTW), a part of which is accepted for PHM19 (Choudhury, Hong \& Dhupia, 2019a).

Table 1. Timeline of the proposed research

\begin{tabular}{|c|c|c|c|c|}
\hline Deliverables & $\begin{array}{c}2017-18 \\
\text { (Nov-Oct) }\end{array}$ & $\begin{array}{l}2018-19 \\
\text { (Nov-Oct) }\end{array}$ & $\begin{array}{l}2019-20 \\
\text { (Nov-Oct) }\end{array}$ & $\begin{array}{l}2020-21 \\
\text { (Nov-Oct) }\end{array}$ \\
\hline Objective 1 & & $=$ & & \\
\hline $\begin{array}{l}\text { Literature review } \\
\end{array}$ & & & & \\
\hline Analytical modelling & & & & \\
\hline Objective 2 & & & & \\
\hline $\begin{array}{l}\text { Detection algorithm and } \\
\text { validation for gears }\end{array}$ & & & & \\
\hline $\begin{array}{l}\begin{array}{l}\text { Detection algorithm } \\
\text { validation for bearings }\end{array} \\
\end{array}$ & & & & \\
\hline Objective 3 & & & & - \\
\hline $\begin{array}{l}\text { Statistical methods for fault } \\
\text { severity estimation }\end{array}$ & & & & \\
\hline Objective 4 & & & & - \\
\hline Test-rig development & & & & \\
\hline Experiments & & & & \\
\hline Conference papers & & & & \\
\hline Journal papers & & & & \\
\hline Thesis writing & & & & \\
\hline
\end{tabular}

In this algorithm, VMD was utilized to decompose the original multi-component gear fault vibration signal obtained from the analytical model, into its different constituent modes. Then the mode having instantaneous frequency centering the gear-mesh frequency was chosen to be treated with DTW, which helps in removing spectral smearing appearing due to speed fluctuations.

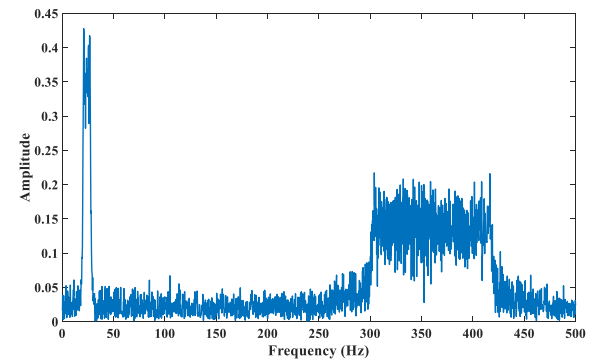

Figure 2. The spectrum of the original vibration signal of the simulated gearbox in fault condition in the presence of speed fluctuation and noise.

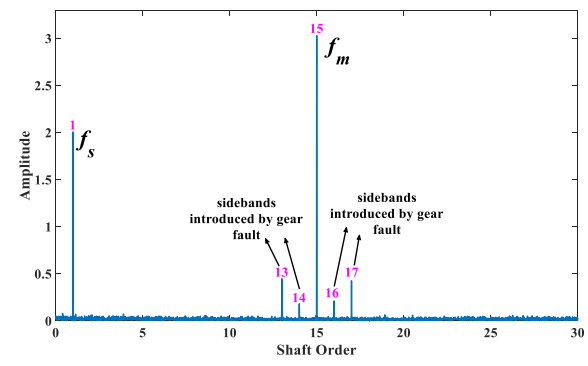

Figure 3. The shaft order spectrum of the gearbox in fault condition after the application of the proposed algorithm.

Fig. 2 shows the spectrum of the original signal, obtained for a time-varying speed condition. Smearing is evident which makes it difficult to extract any reliable fault information (presence or absence of sidebands around the gear-mesh frequency) from it. Fig. 3 shows the generated shaft order spectrum after the application of the developed detection algorithm. It can be observed that the severe spectral smearing caused by the speed fluctuations is removed and the sidebands introduced due to gear faults can be easily identified. Thereafter, the fault detection algorithm was 
validated using measured vibration signals from a three-stage $750-\mathrm{kW}$ wind turbine gearbox, with faulty sun gear and annulus gear planetary stage.
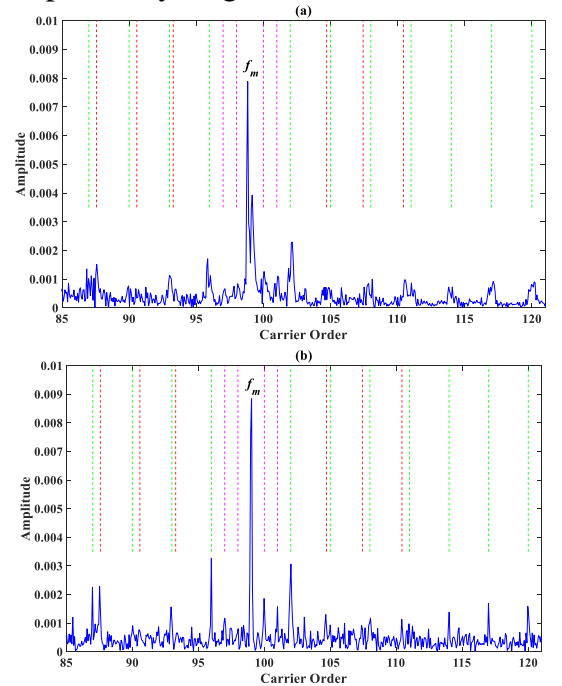

Figure 4. Order spectrum around the fundamental gear-mesh frequency of the planetary gear set (a) before and (b) after the proposed algorithm.

Fig. 4 (a) and 4 (b) show the carrier order spectrum before and after the application of the developed detection algorithm. Thus, the fault detection algorithm is validated using signals from an analytical model as well as from an industrial drivetrain. A complete version of this work is being prepared as a journal article (Choudhury, Hong \& Dhupia, 2019b).

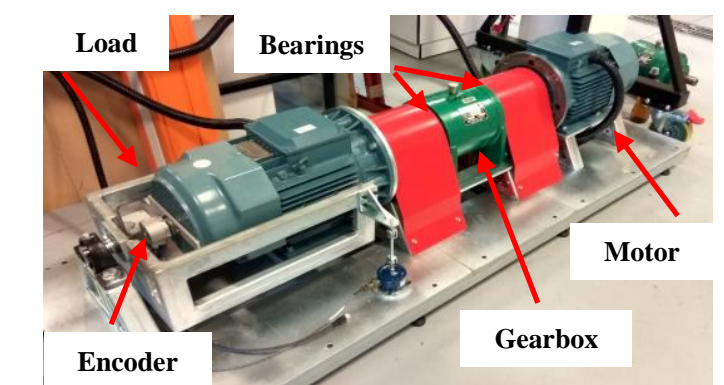

Figure 5. Industrial drivetrain test-rig developed at the University of Auckland.

Test-rig development: An electromechanical drivetrain testrig, consisting of a $7.5-\mathrm{kW}$ induction motor, a $7.5-\mathrm{kW}$ twostage planetary gearbox and a $7.5-\mathrm{kW}$ generator load, is being developed for further validation work. Fig. 5 shows the testrig, which is operated using a variable frequency drive (VFD), making it possible to simulate different drivetrain failure modes under various conditions of speed and load variations.

\subsection{Remaining Work}

- Bearing fault detection: Analytical modeling in order to understand the bearing signal characteristics is ongoing.
The next step is to extend the VMD and DTW based detection algorithm for identifying bearing faults.

- Fault severity model: Once fault detection algorithms are developed and validated, fault severity prediction methods based on statistical parameters of measured vibration signal will be developed.

\section{CONClusion}

This research provides a framework for fault diagnostics in industrial drivetrains, like wind turbines etc. Bearings and gears are identified as the two critical components that contribute maximum to drivetrain failures. A novel selfadaptive fault detection technique for industrial gears is developed in the initial phase, which can reliably detect fixed-axis and planetary gear faults under inherent speed and load fluctuations. The next phase of this research will focus on applying the detection technique for bearings followed by the development of a fault severity prediction model.

\section{REFERENCES}

Cerrada, M., Sánchez, R., Li, C., et al., (2018). A Review on Data-driven Fault Severity Assessment in Rolling Bearings. Mechanical Systems and Signal Processing, 99 (2018), 169-196.

Choudhury, M. D., Hong, L., and Dhupia, J. S. (2018). A critical investigation of Hilbert-Huang transform based envelope analysis for fault diagnosis of gears. 2018 IEEE/ASME International Conference on Advanced Intelligent Mechatronics, July 9-12, Auckland, New Zealand.

Choudhury, M. D., Hong, L., and Dhupia, J. S. (2019a). Order tracking using variational mode decomposition to detect gear faults under speed fluctuations. Annual Conference of the PHM Society 2019 (PHM19), September 21-26, AZ, USA (abstract accepted, to be presented).

Choudhury, M. D., Hong, L., and Dhupia, J. S. (2019b). A Novel Self-adaptive Fault Detection Algorithm for Multistage Gearboxes Operating under Speed Fluctuations. Mechanical Systems and Signal Processing (to be submitted).

Lie, Y., Lin, J., Zuo, M. J., and He, Z. (2014), Condition Monitoring and Fault Diagnosis of Planetary Gearboxes: A review. Measurement, 48 (2014), 292-305.

Rai, A., and Upadhyay, S. H. (2016). A Review on Signal Processing Techniques Utilized in the Fault Diagnosis of Rolling Element Bearings. Tribology International, 96 (2016), 289-306.

Sheng, S. (2012). Wind turbine gearbox condition monitoring round robin study-vibration analysis. U.S.: USDOE Office of Energy Efficiency and Renewable Energy Wind Program. 